\title{
CARNAVAL DE CÁDIZ Y CINE, UNA RELACIÓN RECÍPRDCA
}

Ignacio Sacaluga Rodríguez y Álvaro Pérez García

\section{AUTORES / AUTHORS:}

Ignacio Sacaluga Rodríguez(*)

Álvaro Pérez García(**)

\section{ADSCRIPCIÓN PROFESIONAL/PROFESSIONAL AFFILIATION:}

(*) Profesor y Director de Área de Comunicación. Facultad de CC. Sociales y de la Comunicación. Universidad Europea de Madrid

$\left.{ }^{(*}\right)$ Profesor Titular del C.U. SAFA - Universidad de Jaén

\section{TÍTULO/TITLE:}

Carnaval de Cádiz y cine, una relación recíproca

Cadiz carnival and film, a reciprocal relationship

\section{CORREO-E / E-MAIL:}

ignacio.sacaluga@uem.es

alvaroperez@fundacionsafa.es

\section{RESUMEN / ABSTRACT:}

El carnaval de Cádiz como elemento de diversidad cultural, desde sus orígenes más concretos -mediados del siglo XVIII-, ha pretendido encontrar fuentes de inspiración en todo tipo de agentes comunicativos y artísticos. Así, por ejemplo, la aparición del cine en España y las primeras proyecciones en 1896 desencadenaron una relación recíproca entre la cinematografía y el carnaval gaditano. Por un lado, el cine recaló en la temática, denominaciones y tipos (disfraces) de las agrupaciones carnavalescas. Por otro, el carnaval gaditano sirvió de escenario y fuente argumental para directores cinematográficos tanto de largometrajes de ficción -fundamentalmente durante los años sesenta- como en género documental a partir del inicio del siglo xxI. Este artículo constituye el avance de una ambiciosa investigación que pretende analizar la relación entre el cine y el carnaval de Cádiz categorizando y catalogando letras y disfraces alusivos al mundo cinematográfico por un lado, y estudiar igualmente las referencias que el cine ha hecho al carnaval de Cádiz.

The Carnival of Cadiz as an element of cultural diversity, from its very inception-during the middle of the XVIII century- has pretended to find sources of inspiration in every kind of communicative and artistic phenomena. For example, the emergence of the cinema in Spain ant the first screenings triggered a reciprocal relationship between cinematography and the Gaditan Carnival. On one hand, the cinema emphasized the themes, denomination and 'tipos' (costumes) of the carnival music groups. On the other hand, the Gaditan Carnival became stage and source of storylines for cinema directors both for fiction -mostly during the seventies- and documentary films from the early beginnings of the XXI century. This article sets up the advance of an ambitious research which intends to analyze the relation between the cinema and the Car- 
nival of Cadiz: categorizing and labelling lyrics and costumes with clear allusion to the film industry on one side, and also studying the clear references of the cinema to the Carnival on the other.

PALABRAS CLAVE / KEYWORDS:

Carnaval; Cádiz; cine; película; agrupaciones de carnaval

Carnival; Cádiz; cinema; film; carnival ensembles 


\section{Introducción}

Expone Sacaluga Rodríguez (2015: 5) que el Carnaval de Cádiz se ha constituido desde sus inicios en una fábrica de creatividad orientada a la generación de coplas, con letra y música original, que han radiografiado la sociedad del momento.

En este sentido, el propio carnaval ha generado una ingente cantidad de información multimedia y multiformato, así «las coplas de las agrupaciones carnavalescas han ejercido de hemerotecas ambulantes que relataban los hechos más destacados ocurridos durante todo el año» (Sacaluga Rodríguez, 2014: 17).

El carnaval ya desde tiempos remotos se asoció a la cultura popular -entendido en sentido laxo pues este término es de reciente concepción- al tiempo que adoptó una vis contestataria, e incluso subversiva, que en ocasiones le sirvió para que el poder establecido le otorgara un cariz peligroso, de este modo el carnaval gaditano ha asumido la función de contrapoder como una de las definitorias. El crítico literario y filósofo del lenguaje soviético Mijaíl Bajtín ahonda en una de sus obras más influyentes - La cultura popular en la Edad Media y en el Renacimiento: el contexto de François Rabelais (Batjín, 2003)- en su concepto de novela como una expresión de la cultura popular carnavalesca y la bufa, como un modo de rechazar aquello impuesto inequívocamente, una manera de cuestionar la inflexibilidad de los patrones literarios. Su discurso carnavalesco se enfrenta, a su modo de entender, a la rígida visión de la realidad. Para Bajtín, la cultura -cómica- popular, enfrentada a la cultura oficial potestad de la Iglesia y el Estado, estaba dominada por los placeres del «bajo cuerpo».

A diferencia de la fiesta oficial, el carnaval era el triunfo de una especie de liberación transitoria, más allá de la órbita de la concepción dominante, la abolición provisional de las relaciones jerárquicas, privilegios, reglas y tabúes [...] El carnaval, en general, no pertenece al dominio del arte. Está situado en las fronteras entre el arte y la vida. En realidad es la vida misma, presentada con los elementos característicos del juego [...] esto puede expresarse de la siguiente manera: durante el carnaval es la vida misma la que juega e interpreta (sin escenario, sin tablado, sin actores, sin espectadores, es decir, sin los atributos específicos de todo espectáculo teatral) su propio renacimiento y renovación sobre la base de los mejores principios (Bajtín, 2003: 12, 13 y 15).

Comparsas, coros, chirigotas y cuartetos se han convertido en sujetos agentes y, a la vez, pacientes de una revolución viral cultural que no ha dejado de crecer y sofisticar una fiesta que nació a la sombra de la tradición oral y que hoy tiene visos de generar nuevos subgéneros culturales que la fusionan, la actualizan y modernizan. A través de las redes sociales contemplamos la internacionalización del carnaval como un proceso que va más allá del conocimiento y celebración de una fiesta de carácter local y que alcanza un estatus musical y cultural seguido por miles y miles de fans en cualquier punto del planeta. Esta es una de 
las razones más destacables que justifica un análisis exhaustivo y en profundidad de cómo ha dejado, el de Cádiz, de ser un carnaval más para convertirse en un subgénero musical que, por cierto, ha influido, como también veremos a lo largo de esta investigación, en formaciones musicales del panorama español e internacional, un ejemplo es Alejandro Sanz, quien reconoce influencias del Carnaval de Cádiz en su manera de componer.

El carnaval gaditano brinda una manera diferente de gestionar, valorar, expresar e incluso, almacenar la información, quizá por su propia idiosincrasia de diversidad cultural o, tal vez, por tratarse de un medio de comunicación que mantiene inalterada su condición de «periodismo cantado» donde todo aquello que no consta en los anales de sus coplas sencillamente no existió, y si ocurrió lo hizo con escasa trascendencia. De ahí que un método muy utilizado en Cádiz para rememorar y datar acontecimientos históricos sea localizar la agrupación carnavalesca que hizo referencia a él en su repertorio. El cariz mediático del Carnaval de Cádiz se desarrollará ampliamente -como ya se ha indicado- más adelante.

Bajo el carnaval se encuentra también un estigma social que, aunque más propio de décadas anteriores, no siempre promovió la diversidad cultural. Hoy, ese estigma nos sirve para revisar el impacto que ha tenido, y probablemente siga teniendo, sobre los diferentes estratos sociales, algo que a su vez concede a la ciudad de Cádiz ciertas características demográficas, migratorias e idiosincrásicas que ejercen una clara influencia sobre el carnaval, sus autores, sus intérpretes, sus seguidores y la ciudad en general. Si bien, en las tres últimas décadas es cuando el Carnaval de Cádiz cumple, no solo con la función de mero cronista, sino como vigilante de los asuntos y poderes públicos, como contrapoder y como transmisor de un legado cultural vasto y diverso.

Pérez García (2015: 38) asegura que, a lo largo de la historia, pocos han sido los temas, aspectos y ámbitos que han escapado de la inventiva y creatividad de los autores de carnaval. Así, el cine como arte, como transmisor de expresiones culturales, como industria o como medio de comunicación se ha convertido en una de las grandes inspiraciones para los tipos (disfraces) y letras del carnaval gaditano desde sus inicios hasta nuestros días. Esto es refrendado por Sacaluga Rodríguez (2016: 65) cuando expone que «es difícil que algo se escape de la retranca carnavalesca, lo que convierte el carnaval gaditano en una gran hemeroteca con más de un siglo de historia, muchas de ellas instaladas en el subconsciente colectivo».

Los orígenes del cine se remontan a los últimos años del siglo xIX, concretamente en España la primera proyección cinematográfica se realizó en 1896 (Bosh et al, 2010: 342). González (2005: 6-7) se refiere a la primera aparición del cinematógrafo en nuestro país, concretamente en Madrid: «Se anticipó el aparato llamado Animatógrafo [...], que ofreció una sesión privada el día 11 de mayo de 1896 e hizo su presentación pública [...] el día siguiente, 12 de mayo». 
Según los datos aportados por el investigador Rafael Garófano, el cinematógrafo llegó a Cádiz durante la primera semana de octubre de 1896.

Los días 14 y 15 de octubre el cinematógrafo se despide del Teatro Principal con funciones exclusivamente de proyecciones, con tres sesiones diarias y 10 cuadros diferentes en cada una, y al día siguiente, 16 de octubre, hace su presentación el segundo proyector que llega a Cádiz, esta vez al Teatro Cómico (Garófano, 1986: 20).

A partir de entonces la relación entre cine y carnaval de Cádiz no ha cesado, siendo ese el motivo de esta investigación en la que se presentará, por un lado cómo se ha retratado el séptimo arte en las coplas y tipos del carnaval gaditano a lo largo de la historia y, por otro lado, se verá también cómo se ha representado el carnaval de Cádiz bajo la mirada de la cinematografía. Asimismo, la investigadora María Luisa Páramo en su tesis doctoral inédita matiza incluso esa relación:

No es extraño encontrar a gran cantidad de profesionales relacionados con la literatura, la música, el humor, el cine, la televisión, la publicidad, que acuden a Cádiz en esas fechas, muchos de ellos de manera asidua, para dejarse sorprender por la creatividad -verbal sobre todo- de los carnavaleros. (Páramo, 2015: 26)

En consecuencia, existen numerosos ejemplos -muchos de ellos citados en esta investigación- de esta complementariedad e interés común entre agentes creativos vinculados al cine y al carnaval gaditano.

\section{Objetivos}

El objetivo general de esta investigación es analizar la relación recíproca entre el carnaval de Cádiz y el Cine.

Este objetivo principal se puede desglosar en otros de carácter más específico:

- Categorizar las temáticas relacionadas con el mundo cinematográfico que alguna vez se hayan tratado en el Carnaval de Cádiz, analizando tipos y letras alusivos al séptimo arte.

- Analizar la repercusión que la temática cinematográfica ha tenido en los autores de carnaval, estudiando las letras dedicadas a la misma.

- Comparar las letras de carnaval históricas con las actuales buscando similitudes y diferencias extrapolándolas a su contexto temporal y social.

- Recopilar y analizar todas las obras cinematográficas que han hecho alusión al Carnaval de Cádiz. 


\title{
3. Metodología
}

La metodología que se utilizará en esta investigación será una metodología cualitativa, utilizando el análisis de contenido como técnica para categorizar y cuantificar la ingente cantidad de información que se está obteniendo.

La investigación documental se basa sobre todo en la revisión de los libretos de las agrupaciones de carnaval de las que hay constancia (desde principios del siglo XIX hasta nuestros días) y que están recopiladas en el Aula de Cultura del Carnaval de Cádiz, centro de documentación más importante que existe sobre el Carnaval de Cádiz. También se está realizando el análisis de diversas obras publicadas sobre el Carnaval de Cádiz y la audición de las propias coplas de carnaval.

El análisis de contenido se realizará con el programa MAX QDA, que es una herramienta para el análisis de texto fundamentado en datos cualitativos, que se basa en la metodología de la investigación social y que se utiliza en muchas disciplinas o ámbitos, como la sociología, las ciencias de la educación, la economía, el marketing, la religión, la etnología, la arquitectura, la planificación urbana, la sanidad pública y la medicina (Revuelta y Sánchez, 2003).

Las categorías más relevantes que han aparecido tras la primera aproximación en este estudio se citan a continuación: Actores y Actrices de cine, Personajes Cinematográficos, Oficios cinematográficos, Títulos de Películas.

\section{El cine en el carnaval de Cádiz}

Un año más tarde de aquella primera proyección -que tuvo lugar el 14 de octubre de 1896-, el que había sido calificado como el invento del siglo ya estaba en las coplas del carnaval. La agrupación Los Abanicos, de 1897, llevaba en su repertorio la siguiente letra:

\author{
En la época presente \\ no hay nada tan floreciente \\ como la electricidad. \\ El teléfono, el micrófono, \\ el tan sin rival fonógrafo, \\ el Pampirulín tintófono \\ el nuevo cinematógrafo [...] \\ Todos esos nombres y muchos más \\ tienen los aparatos de electricidad \\ que han inventado desde hace poco \\ con la idea que el mundo se vuelva loco(1).
}


En los años sucesivos, constan otras tantas coplas que hacen referencia al cinematógrafo, coplas de agrupaciones como: La Murga Alemana, de 1903; Los Molineros, de 1908; o Los Políticos Diplomáticos, de 1914 (Garófano, 1986: 151-153).

Las proyecciones del cinematógrafo marcan desde sus inicios la presencia y los repertorios de las murgas y comparsa, como señala Barceló (2015):

El cine, por entonces mudo, era fuente de inspiración de los grupos de carnaval y uno de los casos más claros es el de Quo Vadis?, película de 1912 basada en la novela del Premio Nobel de Literatura Henrick Sienkiewik (1846-1916). El film se proyectó en Cádiz al año siguiente y sirvió de modelo en 1916 para la vestimenta de La corte de Nerón, de Francisco Guzmán, el Batato (Barceló, 2015: 398-399).

Años más tarde, un hecho carnavalesco constata el calado que el cinematógrafo tenía ya en la sociedad de la época. Cañamaque, uno de los autores más relevantes de aquellos años, en 1925, según afirma Garófano (1986: 155) «puso letra y música a las coplas de la comparsa Fantones o la Banda de los 13, nombre de clara influencia cinematográfica, y que venía a demostrar con sus letras la influencia social del cine».

La moda de aludir al cine en las agrupaciones, como era de esperar, comenzó en a principios del siglo xx y aún continúa. De hecho, durante la primera década del siglo así como durante los años 20 y 30 se registraron diversas agrupaciones con nombres relacionados con cualquier aspecto cinematográfico. El investigador Rafael Garófano recoge algunos:

En 1914 salió una comparsa titulada Los Foto-electras, en 1917 La Mano que aprieta, adoptando el título de una de las primeras películas en serie que hicieron furor, en 1927 Chiquilín y sus Tomasines, populares cómicos cinematográficos, en 1928 Los artistas de la pantalla que iban vestidos con trajes de diferentes colores, pitos y revólveres de madera, [...] en 1930 Fatty y sus discípulos recogieron la popularidad del actor norteamericano Roscoe Arbuckle, conocido por todos como el «gordo Fatty», en 1932 Rafles y su pandilla, recordando a uno de los primeros gangsters de la pantalla (Garófano, 1986: 157-158).

La década de los años 30 trae el cine sonoro, un hecho que se produce simultáneamente en toda España, el historiador Emeterio Díez analiza en profundidad la transición de un tipo de cine a otro y sus consecuencias económicas y tecnológicas:

La reconversión de las salas mudas en salas sonoras produce, en un primer momento, un notable incremento de la entrada. Las primeras películas sonoras cuestan a los espectadores más del doble y del triple del precio del cine mudo (entre 4 y 0,80 pesetas) (Díez, 2003: 30). 
En Cádiz, la llegada del cine sonoro se produce en 1931 pues, según el investigador Víctor Manuel Amar (1997: 18) «el primer aparato sonoro que se instaló en Cádiz, lo hizo en el Gran Teatro Falla, inaugurándose el sábado 23 de mayo de 1931, a las 6:30 de la tarde». Se trataba de la película «Rio Rita» basada en una opereta de Florenz Ziegfeid e interpretada por los actores Bebe Daniels y John Boles, «anunciándose que el sistema de sonorización era de la marca Webster Electric, y que los precios de la entrada iban de 3 pesetas la butaca a 0,75 paraíso» (Garófano, 1986: 296).

Como no podía ser menos, el carnaval volvió a dar fe de la sofisticación del invento del cinematógrafo. En 1933, el autor Manuel López Cañamaque estrenó una comparsa llamada Los Zapateros Críticos, en su repertorio ya iba una letra dedicada al cine sonoro, una auténtica crónica de las repercusiones del invento:

El cine sonoro, puedo asegurarle, que ha armado en España la revolución.

Algunos en la cola se llevan tres días, y si les valiera, pedían un colchón.

Yo no sé qué gusto le sacan a eso, pero según dice mi primo José, se quedan las luces como mariposas y hacen unas cosas que ni Dios las ve.

Cuando veo algún pollito pensativo y «demacrao», pienso que aquel angelito viene del cine «mareao» $[\ldots](2)$

Aquel mismo año otra agrupación, Los Iris Carnavalescos, obra de José Poce y Manuel Morilla, entre otros, también le dedicaron una copla al cine sonoro en la que trasladaban ciertas reticencias hacia el nuevo invento por las falsas ilusiones que podría provocar en algunos espectadores.

Dos de los personajes cinematográficos más representados en el carnaval de Cádiz según Barceló (2015: 399-400) han sido:

-«Charlot» (Charles Spencer Chaplin, 1889-1977) en agrupaciones como Troupe de Charlots Sangolotinos (1918); Los Charlot s Zangolotinos (1918) de José Poce; Charlot, Chispa y sus botones (1925); Los Charlots de Candilejas (1958) de Manuel González García y Domingo Botubot o Los Charlots (1973) de José Luis Arniz.

-«Cantinflas» (Mario Moreno Reyes. México, 1911-1993) que llegó a ser pregonero del carnaval de Cádiz en 1986 y cuyo personaje aparecía representado en Los Cantinflas 
(1953) de Manuel León de Juan y otra agrupación del mismo nombre en 1969 original de Manuel Marín García y Juan Reyes Castañeda, Los Cantinfla.

Por otro lado, Barceló (2015) también destaca que:

Todos los géneros cinematográficos han encontrado su espacio en el carnaval de Cádiz y son numerosísimos los tipos de indio, vaquero, gangster o mafioso que han desfilado a lo largo de más de un siglo de concurso, pero hay dos realizadores, ambos norteamericanos, que dejan su huella en la estética carnavalesca gaditana: Walt Disney (Chicago, 1901-Los Ángeles, 1966) y Tim Burton (California, 1958) (2015: 400).

Con respecto al primero, que no solo fue realizador sino que también fue productor, guionista, animador, etc. Su compañía Walt Disney Productions, creada junto a su hermano Roy ha sido la productora de innumerables películas, sobre todo en el terreno de la animación, que han inspirado a los autores de carnaval desde que en 1928 apareció su emblemático ratón, Mickey Mouse. Desde entonces se pueden citar, entre otras, las siguientes agrupaciones basadas en los éxitos de esta productora (Barceló, 2015, p. 400): Los Mickeys (1934); Los gatos Mickeys (1954); Blanca Nieve y los 7 enanitos (1955); Mary Poppins y su conjunto (1969); los coros de la Salle Viña Pinocho (1982) y Los caballitos que suben y bajan (1983); el coro de San Fernando Colorín Colorao (1988); la comparsa Encantamiento (1993); las chirigotas Las Gárgolas (1997), Blancanieves y los siete enanitos (1997) de los hermanos Márquez Mateos y Las madrinas (1998) de Juan Manuel Braza «Sheriff»; la comparsa de Tino Tovar Los Tropicales (2002); la chirigota Las Ajogaillas (más gaditanas imposible) (2007); el cuarteto femenino Las malas, malas que te cagas (2008); las chirigotas Las muchachas del congelao (2009) de «el canijo» o Cai Story (2011) de «el Sheriff»; o las comparsas de 2013, que coincidieron en la idea de representar el personaje de Pepito Grillo, los ubetenses de La voz de la conciencia y Los que te comen el coco, bajo la autoría de Quique Parodi y Luis Gómez.

El pasado año, el cuarteto de Ángel Piulestán y Javi Aguilera representaba el personaje de «Mary Poppins» en Los niños de la Mary (2015).

La estética expresionista, tenebrosa y terrorífica de Tim Burton también ha sido representada en el carnaval gaditano con cierta asiduidad desde que en 1988 apareciese el film «Batman». Desde entonces destacan las siguientes agrupaciones (Barceló, 2015, p. 400): el coro viñero Bátmonos que nos Vamos (1990), la chirigota de los hermanos Márquez Mateos Los extraterrestres (1998) basada en la película «Mars Attack!» al igual que los surrealistas marcianos del Selu Peña Flamenca «Enrique el Alienígena» (2003); las comparsas de 2008 Los Perfumistas de Tino Tovar y La comparsa de Momo de los hermanos Márquez Mateos; el coro a pie de Sevilla Pecci El Maravilloso Mundo de Cadilandia (2009); la comparsa de Romero Bey Los calavera (2009); el coro La pesadilla (2010); la comparsa de An- 
tonio Martín Las locuras de Martín Burton (2011) o la comparsa de Rafael Pastrana Lorenzo, La Prometida (2011).

Estos son algunos ejemplos de agrupaciones que se han basado en películas o personajes concretos de la gran pantalla, el número total sería difícil de concretar. Solo en este último concurso de agrupaciones, 2016, han sido innumerables las agrupaciones inspiradas en el cine o la televisión, como muestra, las siguientes: Los coros La corte o Welcome to cabaret; las comparsas OBDC. La vida es bella!, El creador, El malo del cuento, Los arqueros o Luna Ilena; las chirigotas Los que vienen de marea, Los polvos egipcios, Los que viven de gañote, Yo soy presa, Los niños perdidos o Esto es Hollywood; y los cuartetos Cuento de tronos o Las aventuras de Tontín, entre otras.

\section{El carnaval de Cádiz en el cine}

Como se ha expuesto, a lo largo de sus más de cien años de historia, el cine aparece con asiduidad, como le había ocurrido anteriormente a la prensa y posteriormente a la radio y a la televisión, en las letras de carnaval pero no será hasta los años 60 cuando el carnaval se vea reflejado en la gran pantalla, motivo por el cual se ha decidido situar el cine en este trabajo -a pesar de que cronológicamente es un invento anterior- después de la radio y la televisión.

Ha de tenerse en cuenta que las incursiones del cine en el mundo del carnaval son muy escasas, la mayoría pertenecen a películas enmarcadas en un género costumbrista propio de la España de los años 60, donde el Carnaval de Cádiz aparece como mero escenario.

Una de las agrupaciones que mayor trascendencia tuvo en la gran pantalla fue la ya citada comparsa Los Beatles de Cádiz, nombre con el que se popularizaron Los Escarabajos Trillizos. Como se ha referido anteriormente, este grupo, debido al éxito obtenido dentro y fuera de Cádiz así como en televisión, no tardó en dar el salto al cine. El primer cameo fue en 1966 con Rocío Dúrcal, compartiendo reparto en la película «Acompáñame» (Amadori, 1966).

También participaron ese mismo año en «Europa canta» (Merino, 1966) y dos años más tarde, en 1968, en «El Padre Coplillas» (Comas, 1968).

Unos años antes, en 1961, uno de los autores, -y máximo representante del Carnaval de Cádiz- Paco Alba, junto a su comparsa, aparecieron en la película «La Viudita Naviera» (Marquina, 1961), junto a los actores Paquita Rico, Arturo Fernández y Mary Santpere, entre otros. 
En cuanto al cine documental cabe destacar Febrero. Cuando la Vida es Carnaval (Sacaluga Rodríguez, 2009) una película del autor de esta investigación y que aborda el fenómeno del carnaval gaditano de manera integral (histórica, política, artística, humorística y musicalmente, así como en sus vertientes oficial -Concurso Oficial de Agrupaciones Carnavalescas [COAC]y callejera).

Además, existen otras obras audiovisuales como Carnaval Geografic (Lázaro, 2008) o Nos vemos en la calle (Al Jende et al., 2007), que retratan exclusivamente el carnaval callejero. En el caso de Carnaval Geografic, lo que empezó como un material audiovisual puntual se ha convertido en una guía fílmica indispensable para conocer el fenómeno de las agrupaciones «ilegales».

Bajo el título de Alegrías de Cádiz (García Pelayo, 2014), se estrena en 2014 un largometraje de ficción, dirigido en clave de comedia por Gonzalo García Pelayo, que despliega sobre Cádiz a un grupo de personajes interrelacionados bajo el carnaval y el flamenco. La película incluye actuaciones de agrupaciones carnavalescas de autores consagrados del carnaval oficial. En cuanto a la factura guarda en ocasiones aspectos y giros más propios del género documental o incluso del falso documental, aunque en términos absolutos se acomoda claramente en la ficción.

Otro film, estrenado en el año 2015, es el largometraje The beautiful Cádiz, escrita y dirigida por el sanluqueño Rafael Sadoc y que narra la historia de amor entre Darío Vélez, un comparsista reconvertido en monologuista y una inglesa (Megan) que trabaja en el mundo de las rutas turísticas y que anda un poco harta de la vida por un desengaño amoroso. Aunque no es una película sobre carnaval de Cádiz, este mundo si está muy presente a lo largo del film, formando parte de la trama de la película y enmarcando la historia en la ciudad de Cádiz, que se muestra en todo su esplendor.

El mismo año 2015 se estrenó el documental Mi querida España, que revisa la historia reciente de España a través de las coplas del carnaval de Cádiz y el gran archivo del periodista Jesús Quintero, con más de 5.000 entrevistas. Quintero acuñó, durante su larga carrera de periodista, un inmenso universo de personajes, de todo tipo de registros, que incluía a los que estaban excluidos de la versión imperante en el país. Sus entrevistas reflejan también la palabra que no se pronuncia, y los cuerpos que hablan aunque los sonidos los contradigan; así, sus entrevistas nos devuelven un espejo más rico y complejo donde contemplarnos. Esta narrativa y sus entrevistas, emitidas e inéditas, son la materia prima de este relato de los años de España en democracia.

La última producción cinematográfica, hasta la fecha de publicación de este trabajo, corresponde a la dirigida por Manuel Iborra. Se trata de un largometraje documental titulado La Fies- 
ta de los locos (Iborra, 2016). Esta película, producida por Antonio Resines, trata de descifrar los peculiares códigos culturales y, a la sazón, humorísticos del carnaval callejero gaditano. Para ello realiza un seguimiento de algunas de las agrupaciones callejeras más representativas del carnaval de 2016, año en que se estrena la producción.

\section{Conclusiones}

Si bien la relación entre cine y carnaval de Cádiz se produjo desde prácticamente el nacimiento del séptimo arte, conviene recordar, a título recopilatorio, que el Carnaval de Cádiz como protagonista cinematográfico no tuvo apenas presencia hasta bien entrada la década de los 60, es cuando se utilizan aquellas Fiestas Típicas como expresión folclórica secundaria y decorativa, ajena obviamente al concepto contestatario del carnaval, como un mero escaparate de la «gracia» gaditana, sin otorgarle un mínimo cariz artístico y relegándolo a una disciplina menor. Paralelamente, como era de esperar, la función informativa siempre estuvo presente en el carnaval y, en ese sentido, la aparición del cinematógrafo como invento clave para el siglo xx no fue una excepción.

\section{NOTAS}

(1) Corresponde, como ya se ha dicho, a la agrupación «Los Abanicos», de 1897. Esta copla la recoge Rafael Garófano del archivo privado de coplas del investigador Marcos Zilberman (Garófano, 1986: 151152).

(2) Corresponde, como ya se ha dicho, a la agrupación «Los Zapateros Críticos», de 1933, obra de Manuel López Cañamaque (Garófano, 1986: 160).

\section{BIBLIOGRAFÍA}

AMAR, V. M. (1997): El cine en Cádiz durante la Il República española. Cádiz, Servicio de Publicaciones Universidad de Cádiz.

BAJTíN, M. (2003): La cultura popular en la Edad Media y en el Renacimiento: el contexto de François Rabelais [1965]. Trad. Julio Forcat y César Conroy. Madrid, Alianza Editorial.

BARCELÓ CALATAYUD, A. (2015): El tipo en el carnaval de Cádiz. Propuesta para una catalogación. Cádiz, Q-Book.

BOSH GIRAL, P.; GARCÍA DE LA BANDA, J. F.; PÉREZ PARIENTE, J. y TOURAL QUIROGA, M. (2010):

Protagonistas de la química en España: Los orígenes de la catálisis. Madrid, CSIC.

DÍEZ PUERTAS, E. (2003): Historia social del cine en España. Madrid, Editorial Fundamentos. 
GARÓFANO, R. (1986): El cinematógrafo en Cádiz. Una sociología de la imagen. Cádiz, Fundación Municipal de Cultura, Cátedra Adolfo de Castro.

GONZÁLEZ LÓPEZ, P. (2005): Los inicios del cine en España (1896-1909). La llegada del cine, su expansión y primeras producciones. Barcelona, Liceus, Servicios de Gestión y Comunicación S.L.

PÁRAMO FERNÁNDEZ, M. L. (2015): El Carnaval de Cádiz como factoría de literatura popular. Tesis doctoral inédita. Universidad Complutense de Madrid.

PÉREZ GARCÍA, Á. (2015): «El sistema educativo español bajo la mirada creativa del Carnaval de Cádiz». Creatividad y sociedad, 24, 32-63.

REVUELTA DOMÍNGUEZ, F. I. y SÁNCHEZ GÓMEZ, M. C. (2003): «Programas de análisis cualitativo para la investigación en espacios virtuales de formación». Teoría de la Educación, 4.

SACALUGA RODRÍGUEZ, I. (2014): El Carnaval de Cádiz como generador de información, opinión y contrapoder: análisis crítico de su impacto en línea y fuera de línea. Tesis doctoral inédita. Universidad Europea de Madrid.

SACALUGA RODRÍGUEZ, I. (2015): «Las agrupaciones del carnaval de Cádiz: Un ejercicio creativo de contrapoder». Creatividad y sociedad, 24, 5-31.

SACALUGA RODRÍGUEZ, I. (2016): «Aproximación al impacto del Carnaval de Cádiz en la prensa escrita gaditana».Revista etic@net, 16, 64-87. 